\title{
Complex optimization of parameters for controlling the cycle of internal grinding by the method of dynamic programming
}

\author{
Aleksandra Akintseva ${ }^{1, *}$ and Pavel Pereverzev ${ }^{2}$ \\ ${ }^{1}$ South Ural State University, Department of Engineering and Technology, 454080 Chelyabinsk, Lenin Avenue 76, Russian Federationa \\ ${ }^{2}$ South Ural State University, Department of Automated Engineering Technology,76, Lenin Avenue, Chelyabinsk, 454080, Russian \\ Federationa
}

\begin{abstract}
The technique of designing the optimal cycles of intragrinding processing which allows performing complex optimization of control parameters is presented. As a mathematical optimization technique the method of dynamic programming is used; it allows to take into account any number of optimized control parameters and constraints of the objective function. In this case, this optimization method is not sensitive to the type of mathematical models of the process and the constraints of the objective function. Complex optimization can simultaneously optimize the parameters of the grinding cycle (the number of cycle stages, feed and allowance for the stages), the cutting speed (billet and circle speed of rotation), parameters of the circle characteristics (hardness, granularity, structure, material of grains and bundle) and parameters of technological adjustments (diameter and height of the circle, circle overtravel).
\end{abstract}

\section{Introduction}

Internal grinding is practically the only method of hole final processing which ensures fulfillment of high requirements for accuracy and quality of treated surface. The fulfillment of the drawing requirements for accuracy and quality in the process of internal grinding depends on a variety of technological factors most of which can be set at the beginning of the cycle or directly controlled during the allowance removal process (control parameters of the cycle). Recommendations for the selection of a particular parameter of cycle controlling presented in various normative references $[1,2$,etc.], have a number of significant drawbacks: 1) they based on statistical data from the 1900s and have a wide range; 2) they are designed to calculate the main operating time on machine tools with manual control for the convenience of normalizing operations; 3) they do not take into account the whole complex of technological factors (for example, when choosing the width of the circle only the length of the hole is taken into account); 4) there are no recommendations regarding the choice of the cycle structure, escape of the mandrel, etc. Therefore, enterprises are forced to select parameters of controlling of the cycle manually, leaning against the saved up experience. The cycles selected in this way require additional inputs of production resources; they are not only suboptimal but also not rational because in order to fulfill the requirements of the drawing on accuracy and quality underestimated radial feed rates are assigned. As a result the production capacity of modern $\mathrm{CNC}$ machines is used only by $40-60 \%$. Often the productivity of these machines is lower than that of universal machines, especially for small batches of parts.

In the currently known methods of cycles designing [3-6 and etc.] the control of one cycle parameter (most often a radial feed), i.e. complex optimization of cycle control parameters is not carried out. Separately, it should be noted that in the vast majority of techniques optimization of the cycle structure itself is not considered. The number of stages of the cycle is assumed to be a constant value independent of the initial processing conditions. Most of the cycle design techniques do not use the mathematical optimization method. As a result, the cycles designed according to these methods are rational (they do not guarantee a minimum processing time) and do not ensure compliance with the drawing requirements for accuracy due to the absence of one of the most important and mandatory models of productivity limitations in accuracy of processing operations, which should include not only the limitations associated with the tolerance of diametrical size but also the tolerances of the shape and disposition of the surfaces. It should be noted that the methods of cycles designing do not take into account changes in the processing conditions (blunting of the circle grains, fluctuation of allowance and initial accuracy of the treated surface in a batch of the billets, etc.), what makes them unsuitable for serial production conditions.

\section{Methodology of complex design of internal grinding optimal cycles}

\footnotetext{
Corresponding author: popovaav@,susu.ru
} 
The solution to the problem described above is the complex method of designing of internal grinding optimal cycles, developed by us, which allows performing simultaneous optimization of the control parameters complex of cycle control.

The control parameters of the grinding cycle can be divided into four main groups. The first group includes structural components of the cycle (as the cycle control parameters), namely the number of stages of the cycle, the distribution of the allowance for the steps of the cycle. The second group includes cutting modes - radial and axial feeds, number of billet rotations, and the speed of the circle. The third group includes parameters of the tool - characteristics of the grinding circle (number of graininess, hardening degree, etc.). The fourth group is quite extensive and includes adjustment parameters (type of reverse stroke - working or idle, diameter and height of the circle, value of the circle overtravel, escape of the mandrel, etc.)

Let us calculate the number of control parameters on examples of three- and five-step cycles because the number of control parameters depends on the cycle structure (tab.1).

It is seen from Table. 1 that the number of control parameters is reckoned in tens. Due to the absence of the complex optimization method of all control parameters for grinding operations fulfilled on $\mathrm{CNC}$ machines it becomes clear why in the production conditions cycle is designed manually by the following chain: at first, the parameters of the circle are selected from the specifications of the drawing. Then the machine, cutting modes and parameters of technological adjustment are assigned. The whole process of the operation designing is conducted by the technologist manually from the ranges often intuitively and on the basis of existing experience with an underestimation of the cutting conditions to a level at which the quality of the treated surface is guaranteed. In this situation the design of highperformance operations on CNC machines is impossible on the scale of the entire automated production of the country. Therefore the development of the technique for complex optimization of control parameters for internal grinding operations and the creation of CAD for $\mathrm{CNC}$ machines on its basis is an actual task.

Due to the presence of elastic displacements in the technological system and the inertia of the moving masses the actually removed allowance is not equal to the program feed. Therefore the optimization method uses a model of process control (the model of allowance removal), which reflects the relation between the program feed, actually removed allowance, elastic deformations of the system with all possible combinations of the main technological factors and in all ranges of their allowable variation [9].

The task of cycle optimization for processing of a specific batch of billets requires searching of deterministic regime parameters of the cycle with unstable values of a number of technological limitations and processing conditions.
Table 1. Calculation of the control parameters number for step cycles of internal grinding

\begin{tabular}{|c|c|c|c|c|}
\hline \multirow{2}{*}{$\begin{array}{l}\text { Group of } \\
\text { control } \\
\text { parameters }\end{array}$} & \multirow{2}{*}{$\begin{array}{c}\text { Name of the } \\
\text { control } \\
\text { parameter }\end{array}$} & \multicolumn{3}{|c|}{$\begin{array}{c}\text { The number of control } \\
\text { parameters for a } \\
\text { stepped cycle }\end{array}$} \\
\hline & & $\begin{array}{c}2 \\
\text { stages }\end{array}$ & $\begin{array}{c}3 \\
\text { stages }\end{array}$ & $\begin{array}{c}5 \\
\text { stages }\end{array}$ \\
\hline \multirow[b]{2}{*}{$\begin{array}{l}\text { Structural } \\
\text { components of } \\
\text { the cycle }\end{array}$} & $\begin{array}{c}\text { Number of } \\
\text { cycle stages }\end{array}$ & 1 & 1 & 1 \\
\hline & $\begin{array}{l}\text { Distribution } \\
\text { of } \\
\text { allowance } \\
\text { for the cycle } \\
\text { stages }\end{array}$ & 2 & 3 & 5 \\
\hline \multirow{4}{*}{ Cutting modes } & $\begin{array}{l}\text { Radial feed } \\
\text { on the steps } \\
\text { of the cycle }\end{array}$ & 2 & 3 & 5 \\
\hline & $\begin{array}{l}\text { Axial feed } \\
\text { on the steps } \\
\text { of the cycle }\end{array}$ & 2 & 3 & 5 \\
\hline & $\begin{array}{l}\text { Billet } \\
\text { rotational } \\
\text { speed }\end{array}$ & 1 & 1 & 1 \\
\hline & $\begin{array}{l}\text { Circle } \\
\text { rotational } \\
\text { speed }\end{array}$ & 1 & 1 & 1 \\
\hline \multirow{5}{*}{$\begin{array}{l}\text { Characteristics } \\
\text { of the grinding } \\
\text { circle }\end{array}$} & $\begin{array}{c}\text { Grain } \\
\text { material }\end{array}$ & 1 & 1 & 1 \\
\hline & $\begin{array}{l}\text { Bundle } \\
\text { material }\end{array}$ & 1 & 1 & 1 \\
\hline & Graininess & 1 & 1 & 1 \\
\hline & Hardness & 1 & 1 & 1 \\
\hline & Structure & 1 & 1 & 1 \\
\hline \multirow{4}{*}{$\begin{array}{l}\text { Process } \\
\text { adjustment } \\
\text { parameters }\end{array}$} & $\begin{array}{c}\text { Circle } \\
\text { diameter }\end{array}$ & 1 & 1 & 1 \\
\hline & $\begin{array}{l}\text { Circle } \\
\text { height }\end{array}$ & 1 & 1 & 1 \\
\hline & $\begin{array}{c}\text { Circle } \\
\text { overtravel }\end{array}$ & 1 & 1 & 1 \\
\hline & $\begin{array}{l}\text { Type of } \\
\text { reverse } \\
\text { motion }\end{array}$ & 1 & 1 & 1 \\
\hline & TOTAL & 18 & 21 & 27 \\
\hline
\end{tabular}

This formulation of the optimization problem is the most complex and relates to the field of non-linear programming. Analysis of discrete optimization methods showed that the dynamic programming method (DPM) is the most suitable for cycle's optimization [7]. In Table. 2 a comparative analysis of the DPM speed and exhaustive search for a different number of optimized parameters. The use of DPM is caused by the fact that this method does not require preliminary construction of the area boundary of feasible constraints and is not sensitive to the properties of control models and constraints. The cycle optimization is carried out by the DPM in analogy with the optimization of the transport problem which requires an optimal route on a branched network of roads 
from the starting point to the final [7]. With regard to optimizing of processing cycle, the road map is similar to the «process state variants» for different feeds on different parts of the allowance. In our case the starting point is the initial state of the process (billet parameters, tool characteristics, etc.); the final point is the final state of the process (parameters of the finished part for accuracy and quality, main time, etc.). As a result the problem of searching a cycle having a minimal basic time among various possible variants of cycles arises.

Table 2. Comparative labor input of optimization methods for a different number of optimized parameters

\begin{tabular}{|c|c|c|}
\hline & $\begin{array}{c}\text { Exhaustive } \\
\text { search }\end{array}$ & DPM \\
\hline \multicolumn{3}{|c|}{ Two optimized parameters } \\
\hline $\begin{array}{c}\text { Formula for } \\
\text { calculating the } \\
\text { number of variants }\end{array}$ & $K_{B}=n^{m}$ & $K_{B}=n m^{2}$ \\
\hline$n=2, m=2$ & 4 & 8 \\
\hline$n=5, m=5$ & 3125 & 125 \\
\hline$n=10, m=100$ & $10^{10}$ & 1000 \\
\hline \multicolumn{3}{|c|}{ Five optimized parameters } \\
\hline $\begin{array}{c}\text { Formula for } \\
\text { calculating the } \\
\text { number of variants }\end{array}$ & $K_{B}=\left(\left(\left(n^{m}\right)^{k}\right)^{v}\right)^{d}$ & $\begin{array}{c}K_{B}=n m^{2} k \\
v d\end{array}$ \\
\hline $\begin{array}{c}n=2, m=2, k=2 \\
v=2, d=2\end{array}$ & 65536 & 64 \\
\hline $\begin{array}{c}n=5, m=5, k=3, \\
v=5, d=3\end{array}$ & $210^{+157}$ & $5,62510^{3}$ \\
\hline $\begin{array}{c}n=10, m=100, k= \\
5, \\
v=10, d=5\end{array}$ & $10^{5000}$ & $2,510^{7}$ \\
\hline
\end{tabular}

DPM does not limit the number of optimized control parameters. As a result it becomes possible not only to design the structure of the optimal cycle but also to carry out a complex optimization of the cycle control parameters of all four groups. An increase in the number of optimized parameters leads to a complication of the optimization process (an increase in possible variants of cycle structures, etc.). For example, if the cycle is optimized for only one feed, then the optimization procedure is performed on a flat coordinate grid (Fig. 1). If the cycles for two or more control parameters are optimized, then the optimization procedure is performed in a multidimensional matrix. When optimizing two control parameters - radial $(n)$ and axial feeds $(b)$ threedimensional optimization matrix is used (Fig. 2 and 3). It is necessary to perform the convolution of the threedimensional matrix on the plane to carry out the DPM optimization procedure. As a result, the information cell located at the nodes of the coordinate grid will become more complicated due to the addition of a new optimized parameter - axial feed. In the article [8] an example of optimization of two control parameters for the cycle axial and radial feeds with the help of DPM. The information cell shown in Fig. 4 and 5 allows optimizing the following control parameters: radial feed $(n)$, axial feed speed $(b)$, allowance $(m)$, diameter $(d)$ and height $(T)$ of the circle, number of cycle stages $(z)$.

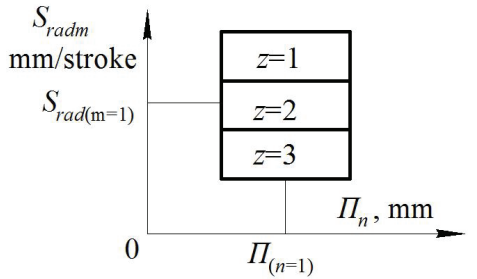

Fig. 1. «Information cell» in the coordinate system «radial feed, allowance», used to optimize two parameters

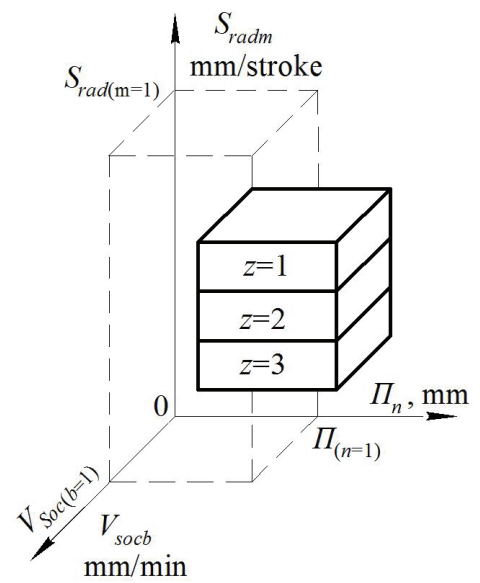

Fig. 2. «Information cell» in the coordinate system «radial feed, allowance», used to optimize three parameters (threedimensional representation)

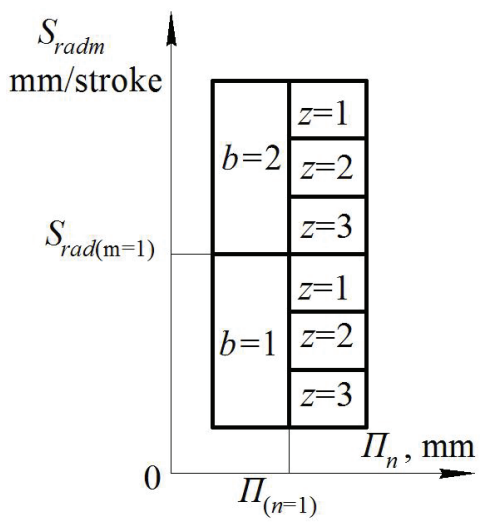

Fig. 3. «Information cell» in the coordinate system «radial feed, allowance», used to optimize three parameters (twodimensional representation)

Thus, the DPM does not limit either the number of optimized control parameters or the number of constraints of the objective function. Constraints imposed throughout the cycle can be divided into two groups. The first group includes constraints imposed during the whole grinding cycle (on the falling of the circle, drive power, admissible range of feeds, etc.). The second group includes constraints imposed at the end of the cycle (accuracy [10], grinding without burn, roughness of the treated surface, etc.). 


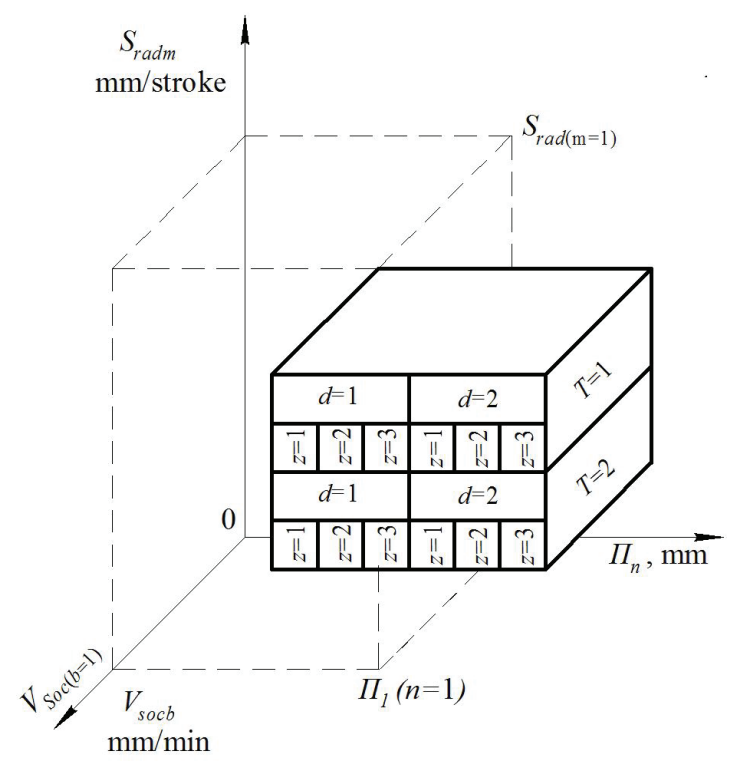

Fig. 4. «Information cell» in the coordinate system «radial feed, allowance», used to optimize five parameters (threedimensional representation)

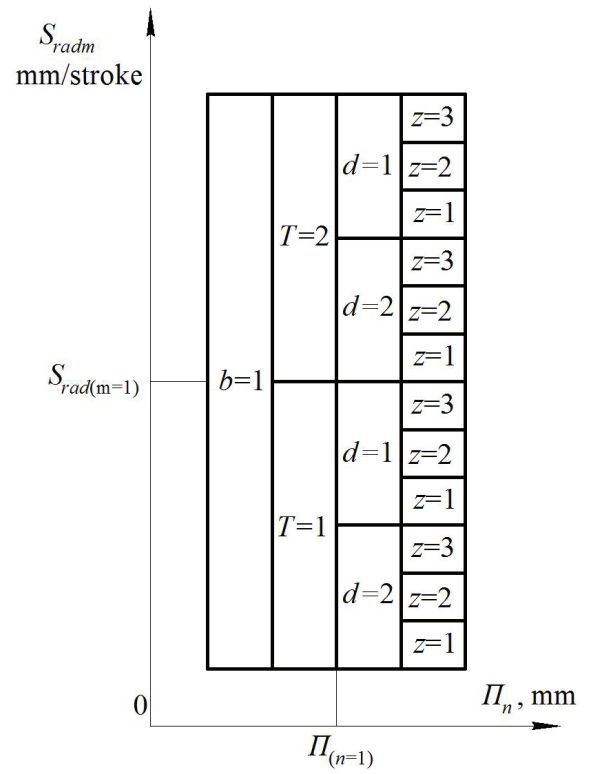

Fig. 5. «Information cell» in the coordinate system «radial feed, allowance», used to optimize five parameters (twodimensional representation)

It should be noted separately that in order to increase the stability of the accuracy and quality of the treated surface to the effect of variable technological factors, verification of the objective function constraints of the DPM should be carried out in two groups of limiting combinations of the values of technological processing conditions. The imposition of constraints of the objective function for each competing stroke is carried out in two variants with the use of both favorable values (minimum values of the bluntness degree of the circle, the initial radial runout of the billet, allowance, maximum diameter of the circle) and unfavorable factors (maximum bluntness of the circle, minimum values of the initial radial runout of the billet, allowance, diameter of the circle).

\section{Conclusion}

1. Despite the emergence of new high-performance $\mathrm{CNC}$ machine tools in domestic engineering industry the problem connected with the existing low productivity of operations performed on these machines has not yet been solved. The reason for this is the lack of reference literature, $\mathrm{CAD}$ and engineering techniques allowing designing cycles for $\mathrm{CNC}$ machines which meet the requirements of modern automated production.

2. Developed technique of complex optimization of control parameters for internal grinding operations allows carrying out the simultaneous optimization of an unlimited number of cycle control parameters (number of cycle stages, feed and allowance for the stages), cutting speed (speed of the billet and the circle), parameters of the circle (hardness, graininess, structure, grain and bundle material) and parameters of technological adjustments (diameter and height of the circle, circle overtravel).

\section{References}

1. D.V. Ardashev, D.E. Anelchik, G. I. Butorin and etc., Modes of cutting for work performed on grinding and finishing machines with manual control and semiautomatic machines: reference book (2007)

2. A.N. Malova and etc., Handbook of the technologist of the machine builder: reference book (1972)

3. S.S. Saykin, P.M. Salov, T.G. Vinogradova, Innovation in the educational process 8, 85 (2010)

4. Y.K. Novoselov, Dynamics of surface formation during abrasive processing (2012)

5. V.N Mikhelkevich, Automatic grinding control (1975)

6. A.A. Nikolaenko, Technology of machine building. 5, 57 (2011)

7. R. Bellman, Dynamic programming (1960)

8. P.P. Pereverzev, A.V. Akintseva, Procedia Engineering 129, 121 (2015)

9. P.P. Pereverzev, A.V. Akintseva, Russian Engineering Research 10, 888 (2016)

10. P.P. Perverzev, A.V. Akintseva, Bulletin of the SUSU. Ser. Mashinostroenie 3, 44 (2016) 